\title{
Variação temporal do tamanho de amostra para experimentos em estufa plástica
}

\author{
Temporal variation of sample size to greenhouse experiments
}

\author{
Leandro Homrich Lorentz ${ }^{1}$ Alessandro Dal'Col Lúcio ${ }^{2}$ Lindolfo Storck $^{3}$ \\ Sidinei José Lopes ${ }^{4}$ Alexandra Augusti Boligon ${ }^{5}$ Ricardo Howes Carpes ${ }^{6}$
}

\section{RESUMO}

\begin{abstract}
O trabalho teve como objetivo estimar o tamanho de amostra em cada colheita, para experimentos realizados em estufa plástica com a cultura do pepineiro do tipo conserva, cultivar Mandarina, na qual se avaliou a da massa da matéria fresca total dos frutos. O cultivo foi realizado na área do Departamento de Fitotecnia-UFSM e se constituiu de seis linhas com doze parcelas de cinco plantas em cada linha. Aplicou-se o teste de Bartlett para verificar a homogeneidade das variâncias entre as colheitas e entre as linhas dentro de cada colheita. Verificou-se que, em 7 das 13 colheitas, as variâncias entre as linhas se apresentaram homogêneas. Os tamanhos de amostras encontrados entre todas as parcelas foram 44 e 22 parcelas e 10 e 11 parcelas por linha para as semi-amplitudes da média de 10 e $20 \%$, respectivamente, a $5 \%$ de probabilidade de erro.
\end{abstract}

Palavras-chave: amostragem; área restrita; controle de qualidade; planejamento de experimentos.

\section{ABSTRACT}

The present work had as objective to estimate the sample size in each crop, for experiments accomplished in plastic greenhouse with the culture of the cucumber of the type conserves, cultivate Mandarina, in which the weight of the total fresh mass of the fruits was evaluated. The cultivation was accomplished in the area of the Department of Fitotecnia - UFSM and it was constituted of six lines with twelve portions of five plants in each line. The test of Bartlett was applied to verify the homogeneity of the variances among the crops and among the lines inside of each crop. It was verified that in 7 of the 13 crops, the variances among the lines came homogeneous. The sizes of samples found among all the portions were 44 and 22 portions and 10 and 11 portions for line for the semi-widths of the average of 10 and $20 \%$, respectively, to $5 \%$ of error probability.
Key words: sampling; restricted area; quality control; planning of experiments.

\section{INTRODUÇÃO}

O pepino é uma espécie de clima quente adaptado a temperaturas amenas, sendo prejudicado pelo frio e morto por geadas (FILGUEIRA, 2000). O ganho térmico a partir do efeito estufa, proteção a pluviosidade, facilidade na realização dos tratos culturais, estabilidade de oferta do produto e incremento na produtividade justificam seu cultivo em ambiente protegido.

A experimentação em cultivos protegidos, assim como em outras áreas, deve ser bem compreendida e executada, pois a precisão caracteriza a qualidade das inferências dos resultados. Os pesquisadores, ao realizarem seus experimentos, esperam que a variabilidade ocorrida entre as parcelas seja atribuída à média e ao efeito de tratamento por eles aplicados. Porém, por mais cuidado que se tenha, ocorrem variações denominadas de erro experimental, conceituado por STEEL et al. (1997), como sendo as variações aleatórias ocorridas entre as parcelas que receberam o mesmo tratamento.

Diversas fontes de erro experimental estão presentes em experimentos e, como não fazem parte de nenhuma exceção, o cultivo em estufa plástica também é afetado por essas fontes de heterogeneidade,

\footnotetext{
${ }^{1}$ Engenheiro Agrônomo, Aluno do Programa de Pós-graduação em Agronomia, Universidade Federal de Santa Maria (UFSM). E-mail: llorentz@bol.com.br.

${ }^{2}$ Engenheiro Agrônomo, Doutor, Professor Adjunto, Departamento de Fitotecnia, Centro de Ciências Rurais (CCR), UFSM. 97105-900, Santa Maria, RS. E-mail: adlucio@ccr.ufsm.br. Autor para correspondência.

${ }^{3}$ Engenheiro Agrônomo, Doutor, Professor Titular, Departamento de Fitotecnia, CCR, UFSM. Bolsista Conselho Nacional de Desenvolvimento Científico e Tecnológico (CNPq). E-mail: storck@ccr.ufsm.br.

${ }^{4}$ Engenheiro Agrônomo, Dr., Prof. Adjunto, Depto Fitotecnia/CCR/UFSM. 97.105-900. sjlopes@ccr.ufsm.br;

${ }^{5}$ Aluno de Graduação do Curso de Agronomia, UFSM. Bolsista da Pró-reitoria de Assuntos Estudantis, UFSM.

${ }^{6}$ Aluno de Graduação do Curso de Agronomia, UFSM. Bolsista do Programa de Iniciação Científica, CNPq.
} 
entre elas: a heterogeneidade do material experimental utilizado, tipos de tratamentos, aplicação não uniforme de tratos culturais, ataque de pragas e doenças, injúrias causadas por sucessivas colheitas na mesma planta e a heterogeneidade de solo, sendo esta citada como sendo a maior fonte de variabilidade entre as parcelas (RAMALHO et al., 2000). Para se contornar a heterogeneidade de solo, segundo STORCK \& LOPES (1997), é necessário adequar a área experimental à precisão escolhida, ao delineamento experimental, ao tamanho e forma de parcelas, ao número de repetições e de tratamentos utilizados.

Em muitos casos, dependendo da variável estudada e da quantidade de subunidades dentro da unidade experimental, para viabilizar a avaliação deve ser utilizada amostragem, e essa não for homogênea e representativa, ocorre um acréscimo no erro experimental, pois um determinado tratamento ora é favorecido, ora é prejudicado por erros de sub ou superamostragem (STORCK \& LOPES, 1997). Limitações de tempo, redução de custos e vantagens do uso de técnicas estatísticas, justificam o uso de planos amostrais, sendo a determinação do tamanho da amostra importante em qualquer experimento científico, pois se este tamanho for menor do que o necessário serão obtidas estimativas pouco precisas, podendo até invalidar o trabalho, enquanto no caso de serem tomadas excessivas amostras, serão despendidos tempo e recursos desnecessariamente.

Em cultivos protegidos, normalmente, o número de plantas amostradas é escolhido empiricamente ou por simples tradição, mas trabalhos como o de SOUZA et al. (2002), avaliando a massa da matéria fresca de frutos abobrinha italiana, em cultivo protegido, mostra que quando as variâncias entre as linhas de cultivo em uma mesma colheita se apresentaram heterogêneas, no caso das variâncias dentro de uma mesma colheita serem homogêneas, devem-se utilizar variâncias ponderadas no cálculo do tamanho da amostra. Segundo os autores, para duas épocas sazonais, há variações no tamanho de amostra conforme variação na colheita e na estação sazonal. Para a cultura do pimentão, LÚCIO et al. (2003) obtiveram resultados semelhantes, mas com intensidade de amostragem superior, com tamanho de amostra igual a 50 e 28 plantas/linha, na estação sazonal verão-outono, e de 56 e 35 na estação sazonal inverno-primavera, utilizando semi-amplitudes do intervalo de confiança (D\%) de $10 \%$ e $20 \%$ da média, respectivamente. STUKER \& BOFF (1998) estimaram o tamanho de amostra para avaliação da queima acinzentada em canteiros de mudas de cebola utilizando média e variância a partir de pré-amostras de 30 plantas. No caso do tamanho de amostra ser superior a trinta, voltava-se ao campo e aumentava-se o número de amostras até 150 plantas. Verificou-se que o número de plantas amostradas variou com o caractere avaliado, o uso de pré-amostras estimou adequadamente os parâmetros populacionais e o número de amostras variou com as épocas de coleta.

Com o objetivo de reduzir para 8, 6, 4 e 2 amostras por parcela para a variável altura da planta de algodoeiro, FREITAS et al. (2001) observaram que a medida que se aumentava o número de amostras o teste $\mathrm{F}$ passou a ser mais eficiente para verificar efeito de tratamento, recomendando 6 plantas por parcela como tamanho de amostra. Com metodologia semelhante, FERNANDES \& SILVA (1996) testaram dois métodos de amostragem (probabilístico e não-probabilístico) e tamanhos de amostra variando de 3 a 15 espigas de milho por parcela, para comprimento e diâmetro da espiga e número de grãos por espiga, em um experimento fatorial arranjo de plantas $\mathrm{x}$ cultivares. Para cada tamanho de amostra previamente definido, foi realizada uma análise da variância, considerando eficiente o tamanho que identificava significância de tratamentos pelo teste $\mathrm{F}$ a $1 \%$ e observaram que nem sempre os maiores tamanhos de amostra foram os mais eficientes, sendo recomendadas 11 espigas por parcela. Também se verificou que os resultados entre os métodos foram discordantes quanto à identificação do efeito de tratamento, sem recomendar método preferencial.

Assim, o trabalho teve por objetivo estimar o tamanho de amostra para experimentos com pepino tipo conserva, avaliando a massa da matéria fresca de frutos, e verificando as variações no tamanho de amostra entre as diversas colheitas realizadas durante o período de maturação dos frutos.

\section{MATERIAL E MÉTODOS}

O cultivo de pepino tipo conserva, cultivar Mandarina, foi conduzido em estufa plástica, localizada no Departamento de Fitotecnia da Universidade Federal de Santa Maria, com latitude: $29^{\circ} 41^{\prime}$ S, longitude: $53^{\circ} 41^{\prime} \mathrm{W}$ e altitude $95 \mathrm{~m}$, sendo o clima da região, segundo a classificação de Köeppen é o Cfa subtropical úmido sem estação seca definida e com verões quentes (MORENO, 1961) e o solo classificado, segundo EMBRAPA (1999), como Argissolo Vermelho distrófico arênico.

A estufa plástica utilizada possui $24 \mathrm{~m}$ de comprimento no sentido Norte - Sul e 10m de largura, com pé direito de $2 \mathrm{~m}$ e altura central $3 \mathrm{~m}$. Constituída de uma estrutura de madeira, modelo arco pampeano, coberta com filme de polietileno baixa densidade, de 100 micras de espessura, mesmo material utilizado nas portas e cortinas laterais. A produção das mudas, o transplante, os tratos culturais, as aplicações de 
defensivos, o tutoramento, as irrigações e as adubações foram realizadas de maneira a proporcionar às plantas melhores condições ambientais para o desenvolvimento e produção, obedecendo as recomendações da cultura (FILGUEIRA, 2000).

O ensaio em branco constituiu-se de seis linhas espaçadas $0,7 \mathrm{~m}$ entre filas e $0,2 \mathrm{~m}$ entre plantas, com 60 plantas/linha, na bordadura cultivouse outra espécie de pepineiro, cujos frutos eram do tipo salada. Cada linha foi subdividida em 12 parcelas constituídas de cinco plantas, perfazendo $1 \mathrm{~m}$ linear por parcela com cada uma identificada pelo número da linha e posição dentro desta, sendo os frutos colhidos e pesados separadamente por parcela, quando estes se encontravam entre 5 e $9 \mathrm{~cm}$ de comprimento. Foram considerados como fatores: massa da matéria fresca de frutos ( $\mathrm{g}$ ) das parcela em cada colheita; o número de colheitas realizadas e o número de parcelas colhidas por colheita.

Para a variável massa da matéria fresca, em cada colheita, calculou-se a média, a variância e os graus de liberdade para cada linha de plantas e para todas as parcelas do ensaio, sendo consideradas apenas as unidades básicas que foram colhidas. Aplicou-se o teste de Bartlett (STEEL et al., 1997) entre as seis variâncias das linhas, obtidas em cada colheita, para verificar a homogeneidade entre as linhas.

Estimaram-se os tamanhos de amostra com três variâncias, a primeira, as variâncias médias, ponderadas pelos graus de liberdade, a segunda, as variâncias máximas entre as seis linhas de cultivo, obtidas dentro de cada colheita, e a terceira, as variâncias entre todas as parcelas, obtidas em cada colheita, entre as 72 parcelas da estufa plástica.

Para se estimar o tamanho ideal de amostra em nível de $95 \%$ de confiança, utilizou-se a fórmula:

$$
\mathrm{n}=\frac{\mathrm{t}^{2}{ }_{\alpha / 2} \mathrm{CV} \%^{2}}{\mathrm{D} \%^{2}}
$$

de acordo com FONSECA \& MARTINS (1996), na qual $\mathrm{D} \%$ é a semi-amplitude do intervalo de confiança em porcentagem da média, sendo utilizado 10, 20,30 e 40\%, $\mathrm{CV} \%$ é o coeficiente de variação e $\mathrm{t}_{\alpha / 2}$ é o valor tabelado com (n-1) graus de liberdade e 5\% de probabilidade de erro. $\mathrm{O}$ valor de $\mathrm{n}$ foi calculado até se estabilizar.

Sendo as parcelas uma amostra do ambiente local, ou seja, para que as estimativas obtidas sejam válidas para toda a região e não só para o experimento, a população pode ser considerada infinita. Nas situações em que o tamanho ideal de amostra calculado for superior a $10 \%$ da população amostrada, é conveniente calcular o tamanho ideal de amostra corrigido para população finita através da equação:

$$
\mathrm{nc}=\frac{\mathrm{n}}{1+\frac{\mathrm{n}}{\mathrm{N}}}
$$

(COCHRAN, 1977), em que $\mathrm{N}$ é a população total, utilizado 12 parcelas por linha de cultivo ou 72 parcelas envolvendo todas as parcelas úteis da estufa plástica.

Para verificar o comportamento das médias e das variâncias da massa da matéria fresca total de frutos, foram plotados num gráfico os valores obtidos, em cada colheita, considerando as unidades básicas por linha e a estufa plástica como um todo. As médias e variâncias ponderadas correspondem à ponderação realizada para a média e a variância com os respectivos graus de liberdade, dentro de cada colheita; a variância máxima corresponde ao valor máximo obtido entre as seis linhas de cultivo, dentro de cada colheita e, média e variância geral correspondem às estimativas obtidas para a média e a variância considerando as 72 parcelas da estufa plástica, dentro de cada colheita.

No intuito de validar as estimativas dos tamanhos de amostra encontrados, realizou-se o ajuste de funções lineares simples entre os valores reais obtidos nas linhas de cultivo (variável independente) e os valores obtidos a partir de amostras de tamanhos n (variável dependente), em cada situação de colheita, para as diferentes semi-amplitudes dos intervalos de confiança das médias, de tal forma que, quanto mais próximo à unidade for o valor obtido do coeficiente de determinação $\left(\mathrm{r}^{2}\right)$, maior será a confiabilidade na amostragem realizada e mais precisa será a resposta obtida nas parcelas. Para a validação da amostragem, retirou-se aleatoriamente, dentro das linhas e em todas parcelas do experimento, amostras de tamanho n, simulando a amostragem recomendada para cada situação específica, sendo a resposta obtida pela amostragem corrigida para 12 e 72 parcelas, respectivamente, para amostragem na linha e na área total da estufa plástica.

\section{RESULTADOS E DISCUSSÃO}

O teste de Bartlett aplicado entre as variâncias das seis linhas, em cada colheita, constatou que as mesmas foram homogêneas em sete (54\%) das 13 colheitas realizadas, sendo elas: $2^{\mathrm{a}}, 3^{\mathrm{a}}, 5^{\mathrm{a}}, 6^{\mathrm{a}}, 10^{\mathrm{a}}$, $12^{\text {a }}$ e $13^{\text {a }}$ colheitas. As restantes se mostraram heterogêneas, assim como para as variâncias ponderadas e máximas de cada colheita, o que indica a necessidade de tamanho de amostra diferenciado entre cada uma das linhas e colheitas. Mas o cálculo de um tamanho de amostra por linha individualmente torna-se pouco prático, sendo este generalizado para todas as linhas dentro da mesma colheita e para todas 
as colheitas. Quando as variâncias se mostraram homogêneas, significa que todas as linhas podem ser representadas pelo mesmo valor de variância e conseqüentemente pelo mesmo tamanho de amostra e este representativo de todas as linhas e, portanto, da respectiva colheita.

Cada parcela representa a produção de cinco plantas e as variações se mostraram muito altas, caracterizadas pela magnitude do coeficiente de variação, chegando a 51,3\% na primeira colheita para as variâncias ponderadas e $68,1 \%$ para variâncias máximas e $89,9 \%$ na quarta colheita para variância geral (Tabela 1). Isto evidencia a dificuldade de observação e conclusão sobre dados que utilizam plantas individuais como parcelas, cuja tendência é o aumento do coeficiente de variação com a redução do tamanho de parcela, segundo OLIVEIRA (1994).

Mesmo sem a disponibilidade na literatura de tabelas de classificação dos coeficientes de variação, como as existentes para ensaios agrícolas de produção de grãos, encontrados em LÚCIO et al. (1999), GOMES (2000) e GOMES \& GARCIA (2002), observou-se que todos os $\mathrm{CV} \%$ obtidos nas colheitas apresentaram-se acima de $30 \%$, e que, provavelmente, devam ser classificados ao menos como alto, caracterizando grande variabilidade dos dados. Essa variabilidade pode ser atribuída a diversos fatores, tais como variações na concentração de fertilizantes no solo ou falhas na homogeneização do mesmo, formando manchas de fertilidade, variações provocadas pelo manejo, por injúrias, pequenas diferenças de tratos culturais no decorrer do experimento e o efeito das sucessivas colheitas. Porém, na condição do experimento, a causa provável da alta variabilidade foi a dificuldade de padronizar o ponto de colheita.

A cultura do pepineiro para conserva apresenta velocidade de maturação elevada, com colheitas diárias ou em dias intercalados, tornando o período do ponto ideal da colheita muito restrito. Assim, se um fruto de determinada parcela deixa de ser colhido e se encontra próximo ao ponto ideal, para próxima colheita, já terá ultrapassado este, inflacionando as variações. Outra influência sobre a variância entre as unidades básicas é de que não são colhidas todas as plantas dentro da parcela e tais variações ocorrem aleatoriamente entre as 72 parcelas do experimento alterando as produções individuais totais das mesmas. Amostras pequenas podem ser mais conclusivas do que a análise de uma população, devido à precisão com que são realizadas as tarefas de coletas de dados, treinamento de pessoal e supervisão das atividades (COCHRAN, 1977). Variações ocorridas nas fases iniciais do experimento, como na semeadura e obtenção das mudas
Tabela 1 - Coeficiente de variação (CV\%) e tamanhos de amostra (em unidades básicas $=5$ plantas) corrigida para diferentes semi-amplitudes em percentagem da média (D\%), obtidas com as variâncias médias ponderadas e máximas das seis linhas de doze unidades básicas e com a variância geral entre todas as unidades básicas da estufa plástica, para a variável massa da matéria fresca dos frutos de pepino do tipo conserva. Santa Maria, RS, 2003.

\begin{tabular}{|c|c|c|c|c|c|}
\hline \multirow{2}{*}{ Colheita } & \multirow{2}{*}{$\mathrm{CV} \%$} & \multicolumn{4}{|c|}{$\begin{array}{l}\text { Semi-amplitudes em percentagem da } \\
\text { média }(\mathrm{D} \%)\end{array}$} \\
\hline & & 10 & 20 & 30 & 40 \\
\hline \multicolumn{6}{|c|}{ Variância média ponderada } \\
\hline 1 & 51,32 & 11 & 8 & 6 & 5 \\
\hline 2 & 40,48 & 10 & 7 & 5 & 4 \\
\hline 3 & 35,23 & 10 & 7 & 4 & 3 \\
\hline 4 & 48,69 & 11 & 8 & 6 & 5 \\
\hline 5 & 32,56 & 9 & 6 & 4 & 2 \\
\hline 6 & 25,37 & 8 & 5 & 2 & 1 \\
\hline 7 & 32,89 & 9 & 6 & 4 & 2 \\
\hline 8 & 28,79 & 9 & 6 & 3 & 2 \\
\hline 9 & 35,65 & 10 & 7 & 5 & 3 \\
\hline 10 & 39,23 & 10 & 7 & 5 & 3 \\
\hline 11 & 35,22 & 10 & 7 & 4 & 3 \\
\hline 12 & 34,62 & 10 & 6 & 4 & 2 \\
\hline 13 & 46,65 & 11 & 8 & 6 & 4 \\
\hline \multicolumn{6}{|c|}{ Variância máxima } \\
\hline 1 & 68,14 & 11 & 10 & 8 & 6 \\
\hline 2 & 61,67 & 11 & 9 & 7 & 6 \\
\hline 3 & 45,58 & 10 & 8 & 6 & 5 \\
\hline 4 & 60,81 & 11 & 9 & 7 & 6 \\
\hline 5 & 56,46 & 11 & 9 & 7 & 6 \\
\hline 6 & 42,92 & 10 & 8 & 6 & 3 \\
\hline 7 & 53,48 & 11 & 9 & 7 & 5 \\
\hline 8 & 39,21 & 10 & 7 & 5 & 4 \\
\hline 9 & 46,72 & 11 & 8 & 6 & 5 \\
\hline 10 & 38,10 & 10 & 7 & 5 & 3 \\
\hline 11 & 54,68 & 11 & 9 & 7 & 5 \\
\hline 12 & 58,73 & 11 & 9 & 7 & 6 \\
\hline 13 & 67,88 & 11 & 10 & 8 & 6 \\
\hline \multicolumn{6}{|c|}{ Variância geral } \\
\hline 1 & 64,51 & 50 & 27 & 16 & 11 \\
\hline 2 & 49,67 & 41 & 19 & 11 & 7 \\
\hline 3 & 52,46 & 43 & 21 & 12 & 8 \\
\hline 4 & 89,92 & 59 & 38 & 24 & 17 \\
\hline 5 & 46,20 & 39 & 17 & 10 & 6 \\
\hline 6 & 36,66 & 31 & 13 & 7 & 3 \\
\hline 7 & 53,48 & 44 & 21 & 12 & 8 \\
\hline 8 & 41,76 & 35 & 15 & 8 & 5 \\
\hline 9 & 53,22 & 44 & 21 & 12 & 8 \\
\hline 10 & 59,21 & 47 & 24 & 14 & 9 \\
\hline 11 & 54,58 & 45 & 22 & 13 & 8 \\
\hline 12 & 49,25 & 41 & 19 & 11 & 7 \\
\hline 13 & 61,13 & 48 & 25 & 15 & 10 \\
\hline
\end{tabular}


ou mesmo no transplante das mesmas, provavelmente apresentam grande contribuição para o acréscimo do erro.

Quanto ao processo de amostragem recomendado seria o de amostragem aleatória simples, no qual se realizam sorteios sucessivos das parcelas, com uso de tabela de dígitos aleatórios, até completar o tamanho previsto, na linha ou em todo o experimento. As parcelas sorteadas deverão ser amostradas até o término das colheitas. As demais parcelas devem ser desprezadas, mantendo-se os tratos culturais, e consideradas como bordadura, sendo este um procedimento utilizado para atenuação de fontes de erro, causado por competição entre parcelas contíguas (STORCK \& LOPES, 1997).

Recomenda-se não amostrar tanto na primeira quanto na última colheita, pois estas apresentaram valores dos coeficientes de variação elevados, em qualquer situação de variância utilizada (Tabela1). O tamanho de amostra ideal passa a ser muito próximo do tamanho da população, sendo então preferível coletar todas as parcelas, evitando assim o erro amostral.

De modo geral, observa-se uma elevada exigência na intensidade de amostragem (Tabela1) em que para semi-amplitude do intervalo de confiança (D\%) de 10\% da média, o tamanho da amostra está muito próximo ao tamanho da população, quando considerada a variância máxima $(\mathrm{VM}) \mathrm{e}$, da $2^{\mathrm{a}}$ à $4^{\mathrm{a}} \mathrm{e}$ da $9^{\mathrm{a}}$ à $12^{\mathrm{a}}$ colheita, considerando a variância média ponderada (VMP), portanto, sendo preferível a não realização da amostragem, mesma situação encontrada por SOUZA et al. (2002) e LÚCIO et al. (2003). Já entre a $5^{\text {a }}$ e a $8^{\text {a }}$ colheita, ao se considerar a VMP, pode-se trabalhar com amostras de nove parcelas colhidas por linha de cultivo, ou seja, reduzir em $25 \%$ o número de parcelas colhidas na fila e, por conseqüência, no experimento.

Para D\% de 20\%, considerando a VMP, entre a $5^{\mathrm{a}}$ e $8^{\mathrm{a}}$ colheita, poderá ser amostrada metade das parcelas, correspondente a seis parcelas/linha, enquanto que nas demais colheitas, aumentar para sete parcelas amostradas por linha, significando uma redução de $41 \%$ no material colhido. No caso de optar em utilizar um $\mathrm{D} \%$ de $30 \%$, pode-se ainda reduzir para quatro parcelas por linha, entre a quinta e a oitava colheita e cinco nas demais. Optando-se pela amostragem com base no $\mathrm{D} \%$ de $40 \%$ a precisão e confiabilidade das inferências realizadas com base nestes dados poderão estar comprometidas devido ao número muito baixo do tamanho da amostra.

Com o uso dos valores das variâncias máximas (VM) de cada linha por colheita, houve uma maior padronização do tamanho da amostra com o passar do tempo de colheita, sendo indicado nove e sete parcelas a serem amostradas, respectivamente para $\mathrm{D} \%$ de 20 e $30 \%$, entre a $2^{\mathrm{a}}$ e $12^{\mathrm{a}}$ colheita.

Quando se retirou amostras aleatórias, a partir de todas as parcelas, com base na variância geral (VG), o número destas variou de 31 (redução de $57 \%$ do total de unidades básicas) a 59 (redução de 18\%) com uma média de 44 parcelas (redução de 39\%) para a semi-amplitude de 10\%. Quando a precisão requerida for de $20 \%$, fazem-se necessárias ao menos 22 parcelas em média (redução de $70 \%$ da população) oscilando entre 13 a 38 parcelas (Tabela1), mostrando uma grande variabilidade nos valores obtidos, não sendo possível uma padronização na recomendação do tamanho da amostra adequada para todo o ciclo da cultura.

Pela tabela 2, verifica-se que, com o aumento na semi-amplitude do intervalo de

Tabela 2 - Coeficientes de determinação, obtidos nas equações de regressão linear simples de primeiro grau, entre as médias reais e as estimadas, para variância média ponderada (Var Pond), variância máxima (Var Máx) e variância geral (Var Geral) em semi-amplitudes em percentagem da média (D\%) de 10, 20, 30 e 40\% da média. Santa Maria , RS, 2003.

\begin{tabular}{|c|c|c|c|c|c|c|c|c|}
\hline \multirow{3}{*}{ Colheita } & \multicolumn{8}{|c|}{ Semi-amplitudes em percentagem da média ( $\mathrm{D} \%)$} \\
\hline & \multicolumn{2}{|c|}{10} & \multicolumn{2}{|c|}{20} & \multicolumn{2}{|c|}{30} & \multicolumn{2}{|c|}{40} \\
\hline & $\begin{array}{l}\text { Var } \\
\text { Pond }\end{array}$ & $\begin{array}{l}\text { Var } \\
\text { Máx }\end{array}$ & $\begin{array}{l}\text { Var } \\
\text { Pond }\end{array}$ & $\begin{array}{l}\text { Var } \\
\text { Máx }\end{array}$ & Var Pond & $\begin{array}{l}\text { Var } \\
\text { Máx }\end{array}$ & $\begin{array}{l}\text { Var } \\
\text { Pond }\end{array}$ & Var Máx \\
\hline 1 & 0,9950 & 0,9937 & 0,8048 & 0,8255 & 0,5939 & 0,8410 & 0,5717 & 0,1639 \\
\hline 2 & 0,9638 & 0,9771 & 0,3783 & 0,5988 & 0,0823 & 0,2405 & 0,4826 & 0,2636 \\
\hline 3 & 0,9148 & 0,9452 & 0,8398 & 0,8405 & 0,8487 & 0,7248 & 0,4098 & 0,9149 \\
\hline 4 & 0,8200 & 0,9700 & 0,7744 & 0,7596 & 0,7975 & 0,6537 & 0,0739 & 0,6676 \\
\hline 5 & 0,7435 & 0,9557 & 0,8630 & 0,9396 & 0,9281 & 0,0827 & 0,4957 & 0,7894 \\
\hline 6 & 0,7315 & 0,8644 & 0,5758 & 0,5684 & 0,1558 & 0,4541 & 0,2003 & 0,1659 \\
\hline 7 & 0,9976 & 0,9925 & 0,9222 & 0,9314 & 0,7698 & 0,9023 & 0,0911 & 0,7544 \\
\hline 8 & 0,8311 & 0,8509 & 0,7572 & 0,8598 & 0,8110 & 0,8309 & 0,7789 & 0,6267 \\
\hline 9 & 0,9867 & 0,9693 & 0,6026 & 0,8983 & 0,6534 & 0,9725 & 0,6915 & 0,8897 \\
\hline 10 & 0,9922 & 0,9575 & 0,8119 & 0,8976 & 0,6753 & 0,8617 & 0,5351 & 0,8923 \\
\hline 11 & 0,9931 & 0,9888 & 0,9027 & 0,9774 & 0,8402 & 0,6987 & 0,8176 & 0,6198 \\
\hline 12 & 0,7077 & 0,8606 & 0,5776 & 0,7435 & 0,6448 & 0,7543 & 0,1635 & 0,4172 \\
\hline 13 & 1,0000 & 1,0000 & 0,7599 & 0,9703 & 0,3601 & 0,6898 & 0,0876 & 0,8108 \\
\hline 13 & 1,0000 & 1,0000 & 0,7599 & 0,9703 & 0,3601 & 0,6898 & 0,0876 & 0,8108 \\
\hline Var geral & 0,8825 & & 0,7673 & & 0,7273 & & 0,4403 & \\
\hline
\end{tabular}

Ciência Rural, v.34, n.4, jul-ago, 2004. 
confiança (D\%), dentro de cada tipo de variância, há uma redução nos valores do coeficiente de determinação $\left(\mathrm{r}^{2}\right)$, indicando que para a amostragem em estufa plástica com a cultura do pepineiro, deve-se optar por utilizar valores de $\mathrm{D} \%$ de até $20 \%$. Esses valores obtidos para o $\mathrm{r}^{2}$ mostram que as estimativas dos tamanhos de amostra poderão ser aplicados na prática com grande confiabilidade, pois variam de 0,5684 para a variância máxima (Var Máx) na $6^{\mathrm{a}}$ colheita a 1,0000 para variância média ponderada (Var Pond) e Var Máx na $13^{\text {a }}$ colheita, com a grande maioria dos valores obtidos acima de 0,80 .

Ao se plotar num gráfico os valores obtidos das médias e variâncias com colheitas (Figura 1), observou-se que o comportamento apresentado não foi uniforme, havendo picos de valores, que podem afetar as estimativas do tamanho da amostra, indicando que realmente deverão ser consideradas as recomendações de amostragem dentro de cada colheita realizada. As variações ocorridas para as duas estatísticas (média e variância) são proporcionais, não afetando de forma significativa o valor do coeficiente de variação. $\mathrm{Na} 9^{\text {a }}$ colheita, por exemplo, o maior valor apresentado para a variância foi compensado pelo também maior valor da média, sendo a colheita mais produtiva e com maior variabilidade entre as parcelas colhidas, com valores do $\mathrm{CV} \%$ de 35,7, 46,7 e 53,2\% respectivamente para as estimativas obtidas com uso das médias e variâncias médias ponderada, máxima e geral. Para estas três formas de estimativas, os valores do CV\% obtidos não foram os maiores, ao contrário do observado na $4^{\mathrm{a}}$ colheita que apresentou, em qualquer situação de cálculo, um dos maiores valores do $\mathrm{CV} \%$, apesar de possuir os valores das médias e variâncias $50 \%$ menor do que o observado na $9^{\text {a }}$ colheita.
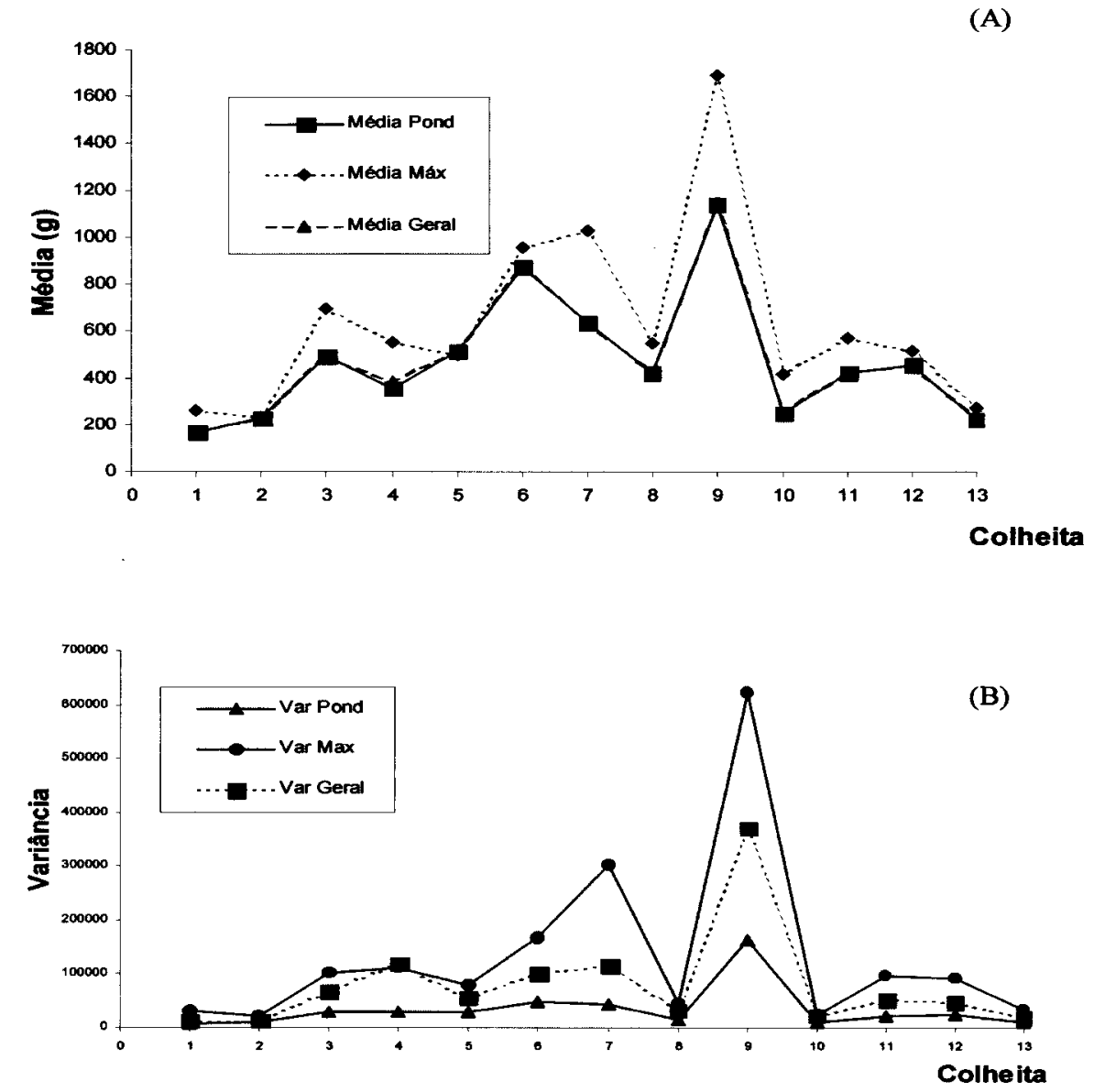

Figura 1 - Média Ponderada (Média Pond), máxima (Média Max) e geral (Média Geral), em gramas/parcela, (A) e variância Ponderada (Var Pond), máxima (Var Max) e geral (Var geral) (B), da massa da matéria fresca total de frutos obtidos em cada colheita, considerando as unidades básicas por linha e a estufa plástica como um todo, para pepino tipo conserva cultivado em estufa plástica. Santa Maria, $\mathrm{RS}-2003$. 


\section{CONCLUSÕES}

O tamanho de amostra para massa da matéria fresca de frutos de pepino, cultivado em estufa plástica, varia em função da colheita. A amostragem deverá ser realizada dentro de cada linha de cultivo, independente da sua intensidade, número da colheitas ou semi-amplitude do intervalo de confiança da média (D\%) adotado. O número de parcelas amostradas em cada linha é de sete para o início e final do ciclo da cultura do pepino e, entre a quinta e oitava colheita de apenas seis parcelas, para um $\mathrm{D} \%$ de $20 \%$, considerando a variância média ponderada e de nove parcelas em todo o ciclo, considerando a variância máxima da linha por colheita.

\section{AGRADECIMENTOS}

\author{
Á Fundação de Amparo à pesquisa do Estado do Rio \\ Grande do Sul_FAPERGS, pelo auxílio financeiro para realização \\ do trabalho.
}

\section{REFERÊNCIAS BIBLIOGRÁFICAS}

COCHRAN, W.G. The estimation of sample size. In: COCHRAN, W.G. Sampling techniques. 3.ed. ew York : John Willey, 1977. p.72-90.

EMBRAPA. Sistema brasileiro de classificação de solos. Brasília, 1999. 412p.

FERNANDES, E.N.; SILVA, P.S.L. Tamanho de amostra e métodos de amostragem para caracteres da espiga do milho. Ciência e Agrotecnologia, Lavras, v.20, n.2, p.252-256, 1996.

FILGUEIRA, F.A.R. Novo manual de olericultura: tecnologia moderna na produção e comercialização de hortaliças. Viçosa: UFV, 2000. 402p.

FONSECA, J.S.; MARTINS, G.A. Curso de estatística. 6.ed São Paulo : Atlas, 1996. 320p.
FREITAS, J.A. et al. Tamanho da amostra para caracterização de plantas de algodoeiro herbáceo. Ciência Rural, Santa Maria, v.31, n.4, p.583-587, 2001.

GOMES, F.P. Curso de estatística experimental. 14.ed. (revisada e ampliada). Piracicaba : Nobel, 2000. 478p.

GOMES, F.P.; GARCIA, C.H. Estatística aplicada a experimentos agronômicos e florestais. Piracicaba : FEALQ, 2002. V.11. 309p.

LÚCIO, A.D.; STORCK, L.; BANZATTO, D.A. Classificação dos experimentos de competição de cultivares quanto a sua precisão. Pesquisa Agropecuária Gaúcha, Porto Alegre, v.5, n.1, p.99-103, 1999.

LUCIO, A.D. et al. Tamanho da amostra e método de amostragem para avaliação de características do pimentão em estufa plástica. Horticultura Brasileira, Brasília, v.21, n.2, p.181-185, 2003.

MORENO, J.A. Clima do Rio Grande do Sul. Porto Alegre : Secretaria da Agricultura, 1961. 46p.

OLIVEIRA, P.H. Tamanho e forma de parcela para avaliação rendimento em experimentos com batata. 1994. $83 \mathrm{f}$. Dissertação (Mestrado em Agronomia) - Curso de Pós-graduação em Agronomia, Universidade Federal de Santa Maria.

RAMALHO, M.A.P.; FERREIRA, D.F.; OLIVEIRA, A.C. Experimentação em genética e melhoramento de plantas. Lavras : UFLA, 2000. 326p.

SOUZA, M.F. et al. Tamanho da amostra para peso da massa de frutos, na cultura da abóbora italiana em estufa plástica. Revista Brasileira de Agrociência, Pelotas, v.8, n.2, p.123-128, 2002.

STEEL, R.G.D.; TORRIE, J.H.; DICKEY, D.A. Principles and procedures of statistics: a biometrical approach. New York : McGraw-Hill, 1997. 666p.

STORCK, L.; LOPES, S.J. Experimentação II. Santa Maria : UFSM, 1997. 197p.

STUKER, H.; BOFF, P. Tamanho da amostra na avaliação da queima-acinzentada em canteiros de cebola. Horticultura Brasileira, Brasília, v.16, n.1, p.10-13, 1998. 